\title{
Prevalence of Iron Deficiency Anemia among the First Grade Students in Primary Schools in Mathpah Area, Sana'a City
}

\author{
Ali A. Alhaj \\ Department of Biochemistry, Faculty of Medicine and Health Sciences, University of Science and Technology, \\ Sana'a, Republic of Yemen
}

\begin{abstract}
Background: Iron-deficiency anemia (IDA) is a common clinical problem throughout the world and an enormous public health risk in developing and even in industrialized countries. Globally, the most significant contributor to the onset of anemia is iron deficiency. In Yemen, current rates of anemia among preschool aged children and pregnant women are $68.3 \%$ and $58.1 \%$ respectively. Aim: To determine the prevalence of iron deficiency anemia (IDA) in the first grade students in primary schools in Mathpah area, Sana'a city. Subjects and Methods: Out of 1300 primary schoolchildren registered in the selected schools, one hundred thirty students were systematically and randomly chosen, aged $5-7$ years ( 56 boys \& 74 girls) from eight primary schools (three governmental basic schools and five private basic schools). Blood samples and questionnaire were collected. Complete blood count, serum iron, and serum ferritin were measured to assess iron deficiency and iron deficiency anemia. All data of the questionnaire and blood tests were analyzed using version 18 of SPSS. Results: In our study, the prevalence of anemia was $5.4 \%$. The prevalence of iron deficiency and iron deficiency anemia were $31.5 \%$ and $3.9 \%$ respectively. Iron deficiency prevalence was $32.1 \%$ among boys and $31.1 \%$ among girls. There is a significant difference between governmental and private schools regarding iron deficiency $(P=$ 0.037). Conclusion: Iron deficiency is prevalent among first grade students in primary schools in Mathpah area, Sana'a city. There is a significant difference between types of schools regarding to iron deficiency.
\end{abstract}

Key Words: School children, serum ferritin, serum iron, Yemen

\section{Introduction}

Anemia is a widespread public health problem associated with an increased risk of morbidity and mortality, especially in pregnant women and young children ${ }^{(1)}$. Globally, the most significant contributor to the onset of anemia is iron deficiency so that IDA and anemia are often used synonymously, and the prevalence of anemia has often been used as a proxy for IDA. It is generally assumed that $50 \%$ of the cases of anemia are due to iron deficiency ${ }^{(2)}$. The global anemia prevalence in pre-school age children and school-age children was 47.4 and 25.4 respectively ${ }^{(3)}$. In Yemen, current rates of anemia among preschool aged children and pregnant women are $68.3 \%$ and $58.1 \%$ respectively ${ }^{(3)}$. Iron deficiency is still considered the most common nutritional deficiency worldwide and the most significant negative consequence of iron deficiency is iron deficiency anemia ${ }^{(4)}$. Iron deficiency is the 
most common form of nutritional deficiency in childhood, affecting all socioeconomic levels of society ${ }^{(5)}$. It is one of the major public health concern in preschool children and pregnant women in the developing countries. Many studies have examined these two at-risk groups; there is a paucity of data on anemia in preschool children living in developing countries ${ }^{(6)}$.

The data on global rates of iron deficiency in developing countries showed that $46 \%$ of children of school age are iron deficient $^{(2)}$. IDA is a common clinical problem throughout the world and an enormous public health risk in developing and even in industrialized countries ${ }^{(7)}$. It leads to weakness, poor physical growth, and a compromised immune systemdecreasing the ability to fight infections and increasing morbidity- and is also thought to impair cognitive performance and delay psychomotor development ${ }^{(7)}$. Intestinal parasitic infection, due to poor hygienic conditions, interferes with iron absorption by reducing it, thus expanding the prevalence of iron deficiency anemia in the developing world ${ }^{(8)}$.

Currently the most important indicator for the iron status is the measurement of ferritin. The plasma content correlates well with the iron stores, and in the first stage of iron deficiency the concentration of ferritin already decreases, which makes it the most sensitive parameter ${ }^{(9)}$. Serum ferritin is a stable glycoprotein, which accurately reflects iron stores in the absence of inflammatory change. It is the first laboratory test to become abnormal as iron stores decrease and it is not affected by recent iron inges-tion. It is an acute phase reactant and levels will rise when there is active infection or inflammation ${ }^{(10)}$.

The Yemeni childhood nutritional problems remain insufficiently explored, and investigation is needed to identify their magnitude and pattern. The prevalence of anemia and iron deficiency among school in Aden governorate, Republic of Yemen was $36.9 \%$ and $19.3 \%$ respectively ${ }^{(11)}$. There is no any study about iron deficiency or iron deficiency anemia in school children in Sana'a, Republic of Yemen.

\section{Subjects and Methods}

A cross-sectional study was carried out from October 2010 to March 2011. Out of 1300 primary schoolchildren registered in the selected schools, one hundred thirty students were systematically and randomly chosen, aged $5-7$ years 56 boys, 74 girls from eight primary schools (three governmental basic schools (78 student) and five private basic schools (52 students). A questionnaire was used that included dietetic history, history of parasitic infestation, and history of any chronic diseases (i.e. renal failure, cardiac diseases, pulmonary diseases, rheumatic diseases, or tumors). The following lab tests were performed on all patients; complete blood count, serum iron, and serum ferritin (to assess iron deficiency anemia). Venous blood samples were obtained from each student, about $5 \mathrm{ml}$ blood were divided into two tubes (EDTA tube) for $C B C$, and (plane tube) to obtain serum for iron studies. Serum was obtained from whole blood by leaving for 10 minutes to clot, then centrifugation at $3000 \mathrm{rpm}$ for 10 minutes. The serum was stored at $-20^{\circ} \mathrm{C}$ for estimation of ferritin and serum iron. Complete blood count (CBC) was performed in the university of science technology hospital (USTH), using $A B X$ PENTRA XL 80 $0^{(12)}$. Serum ferritin test analysis was performed by Elecsys 2010 and serum iron analysis test by Cobas 6000 machine, the electro-chemiluminescence immunoassay "ECLIA" (Roche Diagnostics). Serum iron and serum ferritin were done for all students in Aulaqi Specialized Medical Lab. Approval to conduct the 
survey was granted by the Ethical Committee, University of Science and Technology and Educational office, Maeen area. A consent form for blood collection was obtained from children parents. All parents were informed about the results obtained for their children blood samples.

Criteria for establishment of anemia:

Anemia: hemoglobin $<11.5 \mathrm{~g} / \mathrm{dl}$. Iron deficiency anemia: i) hemoglobin $<11.5 \mathrm{~g} / \mathrm{dl}$, MCV $<80 F L$, serum iron $<60 \mu \mathrm{g} / \mathrm{dl}$ and serum ferritin $<12 \mu \mathrm{g} / \mathrm{l}$ or ii) hemoglobin within normal value, $\mathrm{MCV}<8 \mathrm{oFL}$, serum iron $<60 \mu \mathrm{g} / \mathrm{dl}$ and serum ferritin $<12 \mu \mathrm{g} / \mathrm{l}^{(2,}$ ${ }^{13-15)}$. Or iii) serum iron $<50 \mu \mathrm{g} / \mathrm{dl}$ and hemoglobin within normal value ${ }^{(16)}$.

\section{Statistical analysis}

Data were analyzed using version 18 of SPSS software (Statistical Package for Social Sciences). Chi-square was used for measuring the statistical significance as appropriate. $\mathrm{P}$ values of $<0.05$ were considered statistically significant.

\section{Results}

This study included 130 primary school students registered in the selected schools in Mathpah area, aged 5-7 years ( 56 boys (43.1\%); 74 girls (56.9\%)). Three governmental basic schools (78 student, $60 \%$ ) and five private basic schools (52 students, $40 \%$ ). The mean age of the children was $6.7 \pm 0.4$ yrs. Table (1) shows the laboratory parameters of the studied children. The overall prevalence of anemia $(\mathrm{Hb}<11.5 \mathrm{~g} / \mathrm{dl})$ was $5.4 \%$ (Table 2). The prevalence of iron defi-ciency anemia ( $\mathrm{Hb}<11.5 \mathrm{~g} / \mathrm{dl}, \mathrm{MCV}<80$ $\mathrm{FL}$, Iron $<50 \mu \mathrm{g} / \mathrm{dl}$ or Ferritin $<12 \mu \mathrm{g} / \mathrm{l}$ ) was $3.9 \%$ while non-iron deficiency anemia represen-ted $1.5 \%$ of the study population (Table 3). The pre-valence was 31.5\%. An iron deficient student was defined as every student with normal $\mathrm{Hb}, \mathrm{MCV}<80 \mathrm{FL}$ and either serum iron less than $50 \mu \mathrm{g} / \mathrm{dl}$, or serum ferritin less than $12 \mu \mathrm{g} / \mathrm{L}$. The prevalence of iron deficiency among primary school students according to gender and type of school is shown in Table (5). There was no statistically significant difference between boys and girls regarding iron deficiency $(p=0.897)$, however, a significant difference was observed between governmental and private schools $(p=0.037)$.

Table 1. The laboratory parameters of the study population

\begin{tabular}{|l|l|}
\hline Parameters & Mean \pm SD \\
\hline Age (years) & $6.7 \pm 0.4$ \\
Hemoglobin $(\mathrm{g} / \mathrm{dl})$ & $13.1 \pm 0.9$ \\
PCV\% & $38.90 \pm 2.41$ \\
MCV $(\mathrm{FL})$ & $77.31 \pm 6.93$ \\
MCH $(\mathrm{pg})$ & $25.91 \pm 2.83$ \\
MCHC $(\mathrm{g} / \mathrm{dl})$ & $33.45 \pm 0.92$ \\
RDW & $13.1 \pm 1.34$ \\
Iron $(\mu \mathrm{g} / \mathrm{dl})$ & $41.1 \pm 22.1$ \\
Ferritin $(\mu \mathrm{g} / \mathrm{l})$ & $62.4 \pm 32.4$ \\
\hline
\end{tabular}

$\mathrm{SD}=$ Standard Deviation

Table 2. Anemia among the study population

\begin{tabular}{|l|cc|}
\hline Hemoglobin level & N & $\%$ \\
\hline Low $(<11.5 \mathrm{~g} / \mathrm{dl})$ & 7 & 5.4 \\
Normal $(11.5-15.5 \mathrm{~g} / \mathrm{dl})$ & 123 & 94.6 \\
Total & 130 & 100.0 \\
\hline
\end{tabular}

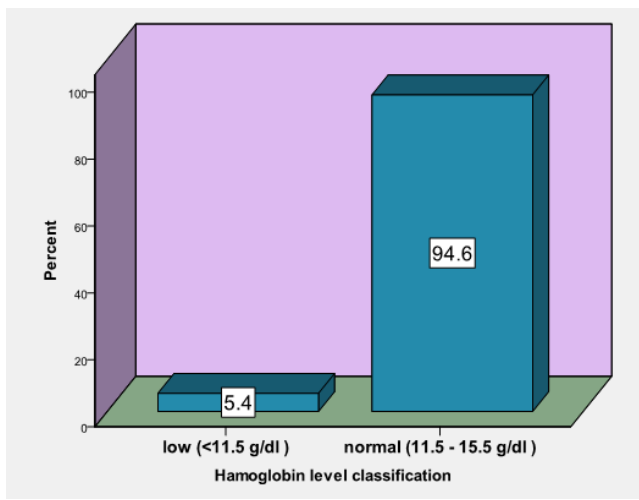

Figure 1: prevalence of anemia 
Table 3. Distributions of IDA, non-IDA and nonanemia between school children

\begin{tabular}{|l|cc|}
\hline Items & $\mathrm{N}$ & $\%$ \\
\hline Iron deficiency anemia & 5 & $3.9 \%$ \\
Non-iron deficiency anemia & 2 & $1.5 \%$ \\
Non anemia & 123 & $94.6 \%$ \\
Total & 130 & $100.0 \%$ \\
\hline
\end{tabular}

\section{Discussion}

The purpose of this study was to determine the prevalence of iron deficiency anemia (IDA) in the first grade students in primary schools in Mathpah area, Sana'a city, Republic of Yemen. The prevalence of anemia in this study was $5.4 \%$. This prevalence is lower than that previously reported in Aden (36.9\%) ${ }^{(11)}$, in Al-mahweet $(20 \%)^{(17)}$, and in Jeddah $(25 \%)^{(18)}$. One explanation is that our study included only the first school-level students (age 5-7 yrs). This result confirms the suggestions from other studies that food consumed by children ages 6-9 years contain higher iron content than that consumed by older age groups explaining the higher prevalence of anemia children more than 7 years ${ }^{(19)}$.

The prevalence of iron deficiency anemia (IDA) in our study was $3.9 \%$. This finding is concurring with previous study, which showed the prevalence of iron deficiency anemia in Palestine primary school students in Qaliqlia city $4.5 \%^{(20) .}$ The results of our study correlate well with Keskin et $\mathrm{al}^{(21)}$. They found that the prevalence of iron deficiency anemia among schoolchildren of different socio-economic status in urban Turkey $3.9 \%$.

Table 4. Iron deficiency among the school children

\begin{tabular}{|l|cc|}
\hline Items & $\mathrm{N}$ & $\%$ \\
\hline Iron deficiency & 41 & $31.5 \%$ \\
Non iron deficiency & 89 & $68.5 \%$ \\
Total & 130 & $100 \%$ \\
\hline
\end{tabular}

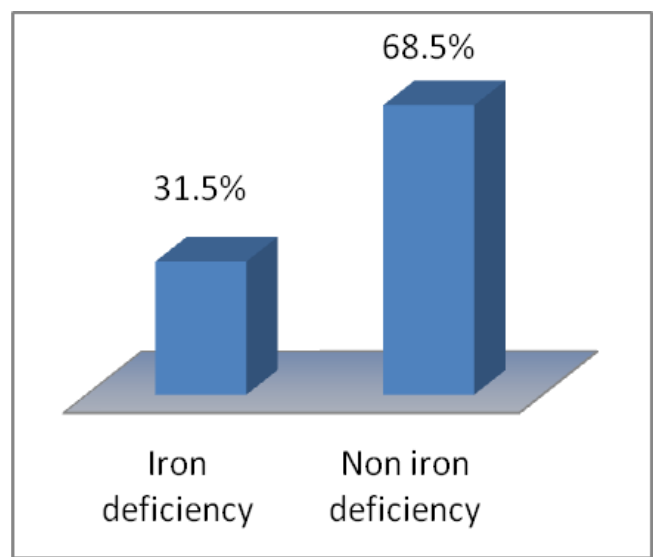

Figure 3: The prevalence of iron deficiency among the school children

Our results are in contrast with that of Manzoor et $\mathrm{al}^{(22)}$, Mamdooh ${ }^{(18)}$. They showed that the prevalence of iron deficiency anemia in Pakistan 10.5\%, $11 \%$ in Jeddah respectively. The prevalence of iron deficiency anemia in our study was less than that in other studies may be because our study was restricted to the first grade in primary school and the number of school and a number of students were less than other studies.

Table 5. Iron deficiency in school children according to sex and type of school

\begin{tabular}{|c|c|c|c|c|c|c|}
\hline \multirow{2}{*}{\multicolumn{2}{|c|}{ Item }} & \multicolumn{2}{|c|}{ Iron deficiency } & \multicolumn{2}{|c|}{ Non-iron deficiency } & \multirow{2}{*}{ p-value } \\
\hline & & $\mathrm{N}$ & $\%$ & $\mathrm{~N}$ & $\%$ & \\
\hline \multirow{2}{*}{$\begin{array}{l}\text { Sex of } \\
\text { children }\end{array}$} & Boys $(n=56)$ & 18 & $32.1 \%$ & 38 & $67.9 \%$ & \multirow{2}{*}{0.897} \\
\hline & Girls $(n=74)$ & 23 & $31.1 \%$ & 51 & $68.9 \%$ & \\
\hline \multirow{2}{*}{$\begin{array}{l}\text { Type of } \\
\text { schools }\end{array}$} & Governmental schools $(n=78)$ & 30 & $38.5 \%$ & 48 & $61.5 \%$ & \multirow{2}{*}{$0.037 *$} \\
\hline & Private schools $(n=52)$ & 11 & $21.2 \%$ & 41 & $78.8 \%$ & \\
\hline
\end{tabular}

*=Statistically significant (Chi-square) 

The prevalence of iron deficiency (ID) in our study was high (31.5\%). This may be due to iron-rich foods is limited in poor families. Furthermore, the absorption of iron is inhibited by polyphenols in tea. Drinking tea with meals is a common habit in our country. Polyphenols containing beverages, such as tea, are known to reduce nonhaeme iron bioavailability by the formation of insoluble complexes ${ }^{(23)}$. Meat products such as red meat, poultry and fish represent excellent sources of haem iron. However, the cost of these products often restricts their access to the poorest in developing countries ${ }^{(24)}$ Citrus fruits have a high content of vitamin C, which is a dietary constituent other than animal tissue that has been reported to augment the absorption of nonhaeme iron in Humans ${ }^{(25)}$.

Table 6. Iron deficiency and drinking tea after a meal

\begin{tabular}{|l|cc|}
\hline Anemia & $\mathrm{N}$ & $\%$ \\
\hline Yes & 26 & $63.4 \%$ \\
No & 15 & $36.6 \%$ \\
Total & 41 & $100 \%$ \\
\hline
\end{tabular}

Percentage of iron deficiency in this study is higher than the percentage of iron deficiency in the study conducted by AlHadrami $^{(11) .}$ Who reported that the prevalence of iron deficiency among school in Aden governorate, Republic of Yemen 19.3\%. Data on global rates of iron deficiency in developing countries shows that $46 \%$ of children of school age are iron deficient $^{(2)}$. The prevalence of iron deficiency in this study is lower than that previously reported in Elminopheyia district, Egypt $(65 \%)^{(26)}$. Differences in between studies could be contributed to different age group studies and methodology of assessment iron deficiency. Regarding gender distribution, the prevalence of iron deficiency in this study was $32.1 \%$ in boys and $31.1 \%$ in girls. There was no statistically significant difference between boys and girls regarding iron deficiency. It was found that there is no statically-significant difference between males and females regarding iron deficiency ${ }^{(21)}$. The prevalence of iron deficiency shows wide variation between governmental and private school. This reflects the level of income for the parents of the students studying in governmental schools and this difference may be attributed to the difference in the number of students in governmental and private schools.

\section{Conclusion}

Iron deficiency is prevalent among first grade students in primary schools in Mathpah area, Sana'a city. There is a significant difference between types of schools regarding to iron deficiency.

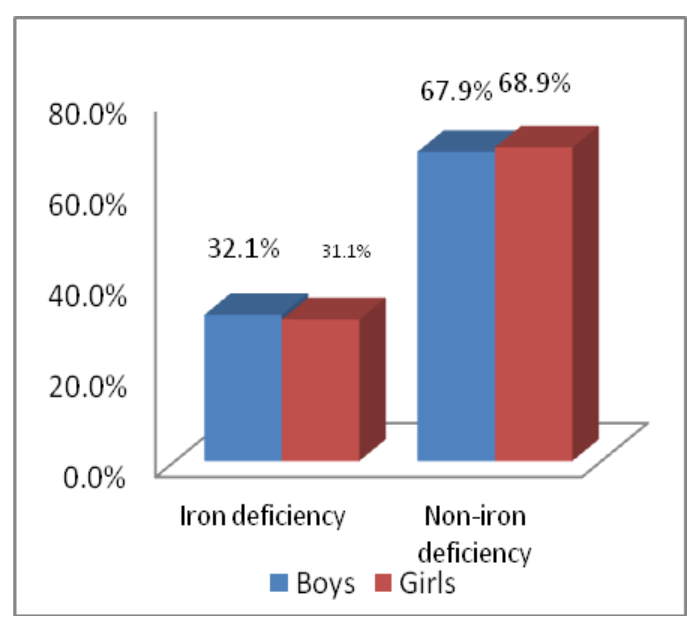

Figure 4: The prevalence of iron deficiency according to gender 


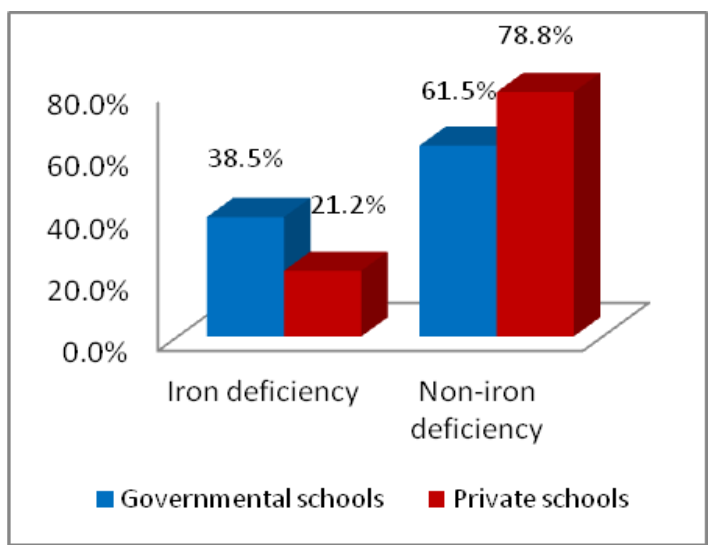

Figure 5: The prevalence of iron deficiency in school children according to type of school.

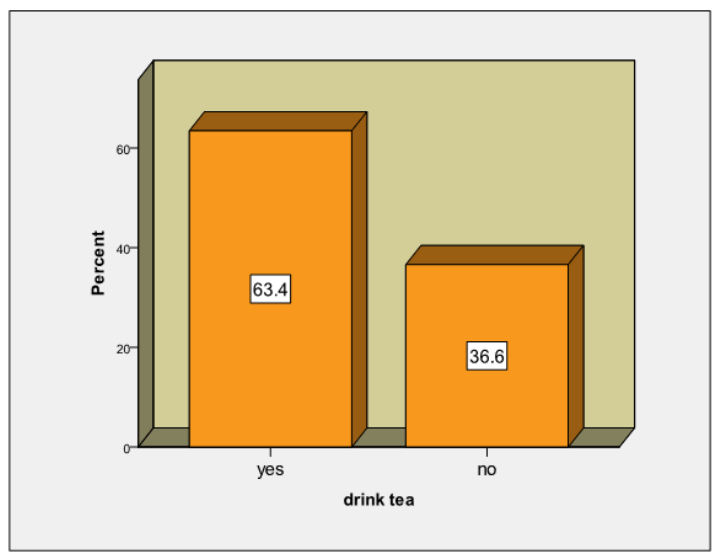

Figure 6: iron deficiency anemia and drinking tea after a meal

\section{References}

1. World Health Organization. The world health report: reducing risks, promoting healthy life. Geneva: WHO, 2002.

2. WHO. Iron deficiency anemia: assessment, prevention, and control. A guide for program managers". Geneva, Switzerland: World Health Organization. (WHO/NHD/ 01.3), 2001.

3. World Health Organization. Worldwide prevalence of anemia 1993-2005. WHO Global Data base of Anemia, 2008.

4. Alquaiz JM, Abdulghani HM, Khawaja RA, Shaffi-Ahmed S. Accuracy of Various Iron Parameters in the Prediction of Iron
Deficiency Anemia among Healthy Women of Child Bearing Age, Saudi Arabia. Iran Red Crescent Med J 2012;14(7): 397-401.

5. Scott PJ. Iron deficiency anemia. In: Behrman RE, Kliegman RM, Jonson HB, Zitelli BJ, Stanton BF, Davis HW (eds). Nelson text book of pediatrics. $18^{\text {th }}$ ed. W.B. Saunders 2007; 2: 1239.

6. Leenstra T, Kariuki SK, Kurtis JD, Oloo AJ, Kager PA, ter Kuile FO. Prevalence and severity of anemia and iron: crosssectional studies in adolescent school girls in western Kenya. Eur J Clin Nutr. 2004; 58(4): 681-621.

7. Kadivar MR, Yarmohammadi H, Mirahmadizadeh AR, Vakili $M$, Karimi $M$. Prevalence of iron deficiency anemia in 6 months to 5 years old children in Fars, Southern Iran. Med Sci Monit 2003; 9(2):100-104.

8. Musaiger AO. Iron deficiency anaemia among children and pregnant women in the Arab Gulf countries: the need for action. Nutr. Health 2002; 16(3):161-171.

9. Hans-Konrad B, Jürgen GE. Diagnosis of nutritional anemia, laboratory assessment of iron status. In: Klaus Kraemer, Michael B. Zimmermann, (eds). Nutritional Anemia c/o SIGHT AND LIFE/DSM Nutritional Products Ltd, Copyright $\odot$ SIGHT AND LIFE 2007.

10. Asif N, Hassan K, Mahmud S, et al., Shams, R. Comparison of serum ferritin levels in three trimesters of pregnancy and their correlation with increasing gravidity. Int $J$ Pathol 2007; 5: 26-30.

11. Al-Hadrami $E$.The prevalence of iron deficiency anemia among school children in Aden city (MSc thesis): University of Aden, Republic of Yemen, 2008.

12. Bain, Barbara J .Blood cells: a practical guide. $4^{\text {th }}$ ed. 2006; chapter 2: page 49.

13. Van den Broek N. Anemia and micronutrient deficiencies. Br Med Bull 2003; 67: 149-160.

14. Heeney MM, Andrews NC. Iron homeostasis and inherited iron overload disorders: an overview. Hematol Oncol Clin North Am 2004; 18(6):1379-1403.

15. World Health Organization/ Centers for Disease Control and Prevention, Assessing the iron status of populations, 2004. 
16. Siberry GK, lannone R. The Harriet lane handbook. $15^{\text {th }}$ ed. St Louis: Mosby USA, 2000.

17. Raja'a YA, Suleiman SM, Elkarib SA, Mubarak JS. Nutritional status of Yemeni school children in Al-Mahweet Governorate. East Mediterr Health J.2001; 7(1-2): 204-210.

18. Mamdooh AG. Prevalence of Iron Deficiency Anemia Among Female Elementary School Children in Northern Jeddah-Saudi Arabia. JKAU Med Sci 2008; $15: 55-65$.

19. Wolde-Gebriel Z, West CE, Gebru H, et al. Interrelationship between vitamin $\mathrm{A}$, iodine and iron status in schoolchildren in Shoa Region, Central Ethiopia. Br J Nutr 1993; 70(2): 593-607.

20.Mahfouz H. The Prevalence of Iron Deficiency Anemia among Primary School Children in Qalqilia City (MSc thesis), AnNajah National University, Nablus, Palestine, 2009.

21. Keskin Y, Moschonis G, Dimitriou M, et al. Prevalence of iron deficiency among schoolchildren of different socio-economic status in urban Turkey. Eur J Clin Nutr 2005; 59(1): 64-71.

22. Manzoor A, Muhammed T, Tahira T. Anemia in school children". Pakistan Postgraduate Medical Journal 2003; 14: 4447.

23. Reddy MB, Hurrell RF, Cook JD. Estimation of nonheme-iron bioavailability from meal composition. Am. J. Clin. Nutr 2000; 71(4): 937- 943.

24. Bhargava A, Bouis HE , Scrimshaw NS. Dietary intakes and socioeconomic factors are associated with the hemoglobin concentration of Bangladeshi women. J. Nutr 2001; 131(3):758-764.

25. Cook JD, Reddy MB. Effect of ascorbic acid intake on nonheme-iron absorption from a complete diet. Am. J. Clin. Nutr 2001; 73(1): 93-98.

26. Alaa A, Gihan AF, Hanan AF, Nagwa AG. Epidemiology of iron deficiency anemia: Effect on physical growth in primary school children, the importance of Hook worms. International Journal of Academic Research 2011; 3: Par II. 